\title{
Evaluation of acute toxicity in mice and subchronic toxicity of hydro- ethanolic extract of Chromolaena odorata (L.) King and Robinson (Fam. Asteraceae) in rats
}

\author{
${ }^{1}$ Ogbonnia S. O, ${ }^{\star 2}$ Mbaka G. O, ${ }^{3}$ Anyika E. N, ${ }^{1}$ Osegbo O. M and ${ }^{4}$ Igbokwe N. H
}

${ }^{1}$ Department of Pharmacognosy, University of Lagos, Lagos, Nigeria.

$2^{2}$ Department of Anatomy, Olabisi Onabanjo University, Remo Campus, Ogun State, Nigeria.

${ }^{3}$ Department of Clinical Pharmacy and Biopharmacy, University of Lagos, Lagos, Nigeria.

${ }^{4}$ Department of Pharmaceutical Technology and Pharmaceutical Microbiology, University of Lagos, Lagos, Nigeria.

"Corresponding Author, G.O. Mbaka, E-mail: mbaaka@yahoo.com

GSM: 234-805-8426729

\section{ABSTRACT}

This study was aimed at evaluating the phytochemical profile, acute and subchronic toxicity of C.ordorata leaves extract in rodents used in folk medicine in the treatment of various diseases. Toxicity of the preparation was evaluated in Swiss albino mice by administering orally graded doses of the extract in the ranges of $1.0 \mathrm{~g}$ to $20.0 \mathrm{~g} / \mathrm{kg}$ body weight to the animals and observed continuously for the first $4 \mathrm{~h}$ and hourly for the next $12 \mathrm{~h}$, then 6 hourly for $56 \mathrm{~h}$ ( $72 \mathrm{~h}$, acute toxicity). Wistar rats were also fed with different doses of the extract for 35 days and the effects on some tissues - heart, liver and testes - were histologically examined. Also the effects on the biochemical and haematological parameters were evaluated. The median acute toxicity value $\left(L_{50}\right)$ of the extract was determined to be $16.50 \mathrm{~g} / \mathrm{kg}$ body weight. The extract significantly reduced $(p \leq 0.05)$ plasma glucose and low density lipoprotein (LDL)-cholesterol levels, but increased high density lipoprotein (HDL)-cholesterol in the treated groups compared to the control. Significant increase in the body weight was observed except in the group treated with the highest dose that experienced decrease in weight after twenty days of treatment. Aspartate aminotransferases (AST) and creatinine levels were significantly increased while significant decrease in alanine aminotransferases (ALT) level, calcium and phosphorus levels were observed in all the treated groups. The high $L_{50}$ value $(16.50 \mathrm{~g} / \mathrm{kg}$ body weight) of the extract implies that it could be safe in one dose treatment. The study also revealed that the extract had good hypoglycemic effects and favourable reducing effects on the cardiovascular risk factors. However it was observed that long term use especially at a high dose could have deleterious effect on the heart

Keywords: Acute toxicity, sub-chronic toxicity, Chromolaena odorata

\section{INTRODUCTION}

Chromolaena odorata formerly known as Eupatorium odoratum (Fam. Asteraceae) is a fast growing perennial weed found mostly in farmlands. It was first noticed in Nigeria especially in the eastern part of the country in 1960s hence its Igbo vernacular name of "Obealiofulu" meaning a "new comer". This fast spreading weed became a big relief as fodder for domestic animals. The medicinal uses of the weed were largely exploited by traditional herbalists and were found useful in the management of a number of diseases. A formulation prepared from the aqueous extract is employed locally in the treatment of malarial infection and its antimalarial activity against
Plasmodium falciparium $\mathrm{K} 1$ strain has been scientifically evaluated (Peisutthanan et al., 2005). It was found to be effective as anti-Staphylococcus and anti-Escherichia coli (Peisutthanan et al., 2005; Ling et al, 2007). The plant extract was also found to have potent anti-HSV-I activity and has been screened for such activities (Peisutthanan et al., 2005).

C. odorata extract owes its biological activities to the presence of a mixture of natural product compounds comprising polyphenol with flavonoids as the major constituent and alkaloids. At least ten different flavonoids have been isolated and characterized among which are 3, 5, 4'-trihydroxy-7methoxyflavone, $\quad 5, \quad 7, \quad 3$ '- $\quad$ trihydroxy-5'- 
Agric. Biol. J. N. Am., 2010, 1(5): 859-865

methoxyflavone and 3, 5, 7- trihydroxy-4'methoxyflavone (Ling et al., 2007),

It is also associated with other physiological activities such as antioxidant and anti-inflammation (Peisutthanan et al., 2005). The antioxidant activities of the weed could be attributed to its rich flavonoid contents and has been exploited locally by the traditional herbalists in the management of diabetes (Personal communication with herbalist Ozougwu Gabriel on March 20, 2009 in Lagos on the traditional use of Chromolaena odorata). C. odorata aqueous or alcoholic extract preparations are currently being used locally in the treatment of various diseases and may be administered in certain disease conditions over a long period of time without a proper dosage monitoring.

The use of herbs and herbal formulation for medication is rapidly on the increase. Incidence of renal and hepatic toxicity has been recorded with the ingestion of the medicinal herbs particularly at high doses (Pieme, 2006), hence the need for systemic approach in evaluating their efficacy and safety profile.

This study was therefore designed to evaluate the safety of $C$. odorata extract by carrying out the acute and subchronic toxicity studies in the animal model.

\section{MATERIALS AND METHODS}

Plant material: The $C$. odorata leaves were collected from a suburb in the Lagos metropolis and were authenticated by Mr.T. K. Odewo at Federal Institute of Forestry Research, Ibadan, Nigeria where voucher specimen was deposited at the Herbarium with number $\mathrm{FHI} 108290$. The plant materials were dried at an ambient temperature between $35-45^{\circ} \mathrm{C}$ in an oven for four days, and powdered to coarse particles. $500 \mathrm{~g}$ of the powder was macerated with ethanol $(80 \%)$ at room temperature for seven days with stirring at intervals. After filtration, the solvent was removed under reduced pressure in a rotary evaporator at a temperature below $50^{\circ} \mathrm{C}$ and dried to obtain a weight of $22.45 \mathrm{~g}(4.49 \mathrm{w} / \mathrm{w} \%$ yield).

Acute toxicity study: The toxicity study was carried out using thirty-five (35) male and female Swiss albino mice weighing $20-25 \mathrm{~g}$ each. The animals were randomly distributed into one control group and six treated groups, containing five animals per group. They were maintained on animal cubes (Livestock Feeds Nigeria Ltd), provided with water ad libitum and were allowed to acclimatize to the laboratory conditions for seven days before the experiment.
After depriving the animals of food overnight, the control group received $0.3 \mathrm{ml}$ of $2 \%$ Tween 80 solution orally while each treated group received orally the hydroalcoholic extract prepared by dispersing $8.0 \mathrm{~g}$ in $10 \mathrm{ml}$ volume of $2 \%$ Tween 80 in the doses as follows: 1.0, 2.5, 5.0, 10.0, 15.0 and $20.0 \mathrm{~g} / \mathrm{kg}$. The animals were observed continuously for the first $4 \mathrm{~h}$ and then each hour for the next $24 \mathrm{~h}$ and at 6 hourly intervals for the following $48 \mathrm{~h}$ after administering the extract, to observe any death or changes in general behaviour and other physiological activities (Shah et al., 1997; Bürger et al., 2005)

Subchronic test: Male and female Wistar rats weighing $160 \pm 10 \mathrm{~g}$ were used. They were allowed to acclimatize to the laboratory conditions for seven days and were maintained on standard animal feeds and provided with water ad libitum. The animals were weighed and divided into five groups of five animals each. After fasting the rats overnight the control group received a dose of $0.5 \mathrm{ml}$ of $2 \%$ Tween 80 solution orally once a day for 30 days. The four treated groups respectively received the following doses: $50,100,250$ and $500 \mathrm{mg} / \mathrm{kg}$ body weight of the hydroalcoholic extract (prepared as in the acute toxicity) orally once daily for 30 days (Pieme et al., 2006; Joshi et al., 2007; Mythilypriya el al., 2007). The animals were then weighed every five days, from the start of the treatment, to note any weight variation. At the end of the treatment, they were made unconscious by cervical dislodgement and blood was collected via cardiac puncture into two tubes: one containing EDTA for analysis of haematological parameters and the other containing heparin for biochemical estimations. The collected blood was centrifuged within 5 min of collection at $4000 \mathrm{~g}$ for $10 \mathrm{~min}$ to obtain plasma, which was analyzed for total cholesterol, total triglyceride, and HDL-cholesterol levels by precipitation and modified enzymatic procedures from Sigma Diagnostics (Wasan et al., 2001). LDL-cholesterol levels were calculated using Friedwald equation (Crook, 2006). Plasma was analyzed for alanine aminotransferase (ALT), aspartate aminotransferase (AST), and creatinine by standard enzymatic assay methods (Sushruta et al., 2006). Plasma glucose and protein contents were determined using enzymatic spectroscopic methods (Hussain and Eshrat, 2002). Haematocrit was estimated using the methods of Ekaidem et al. (2006). Haematocrit tubes were filled by capillary action to the mark with whole blood and the bottom of the tubes sealed with plasticide, and centrifuged for 4 - 5 min using haematocrit centrifuge. The percentage cell volume was read by sliding the 
tube along a "critocap" chart until the meniscus of the plasma intersects the $100 \%$ line. Haemoglobin contents were determined using cyanmethaemoglobin (Drabkin) method (Ekaidem et al., 2006).

Phytochemical evaluation of the crude extracts: Phytochemical screening of the extract for the presence of secondary metabolites was performed using the following reagents and chemicals: alkaloids with Mayer reagent and Dragendorff's reagent
(Farnsworth, 1966; Harborne, 1998), flavonoids with the use of $\mathrm{Mg}$ and $\mathrm{HCl}$ (Silva et al., 1998; Houghton and Raman, 1998); tannins with $1 \%$ gelatin and $10 \%$ $\mathrm{NaCl}$ solutions and saponins with ability to produce suds (Houghton and Raman, 1998).

Statistical analysis: All data collected were summarized as mean \pm sem. Significant differences were determined using a Student's t- test and the differences were considered significant if $p<0.05$

Fig. I: Percentage increase in weight of the control and animals treated with different doses of $C$.ordorata hydroethanolic extract

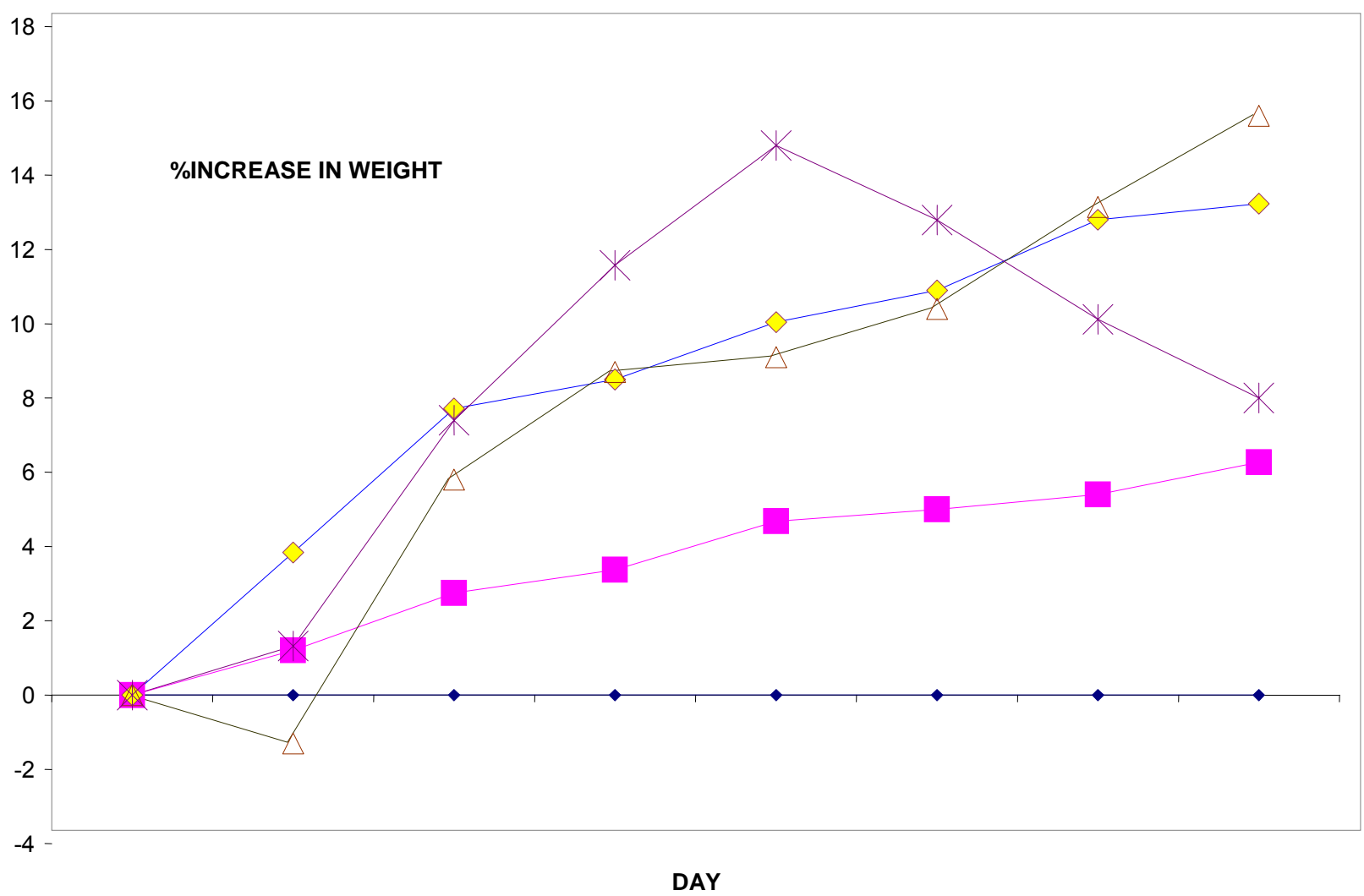

Fig. 2: The histology of testes of the control group Al and treated animals A2 with $500 \mathrm{mg} / \mathrm{kg}$ body weigh of the extract. The arrow shows the somniferous tubules ( $H$ and $E$ stain). mag. $x 100$.
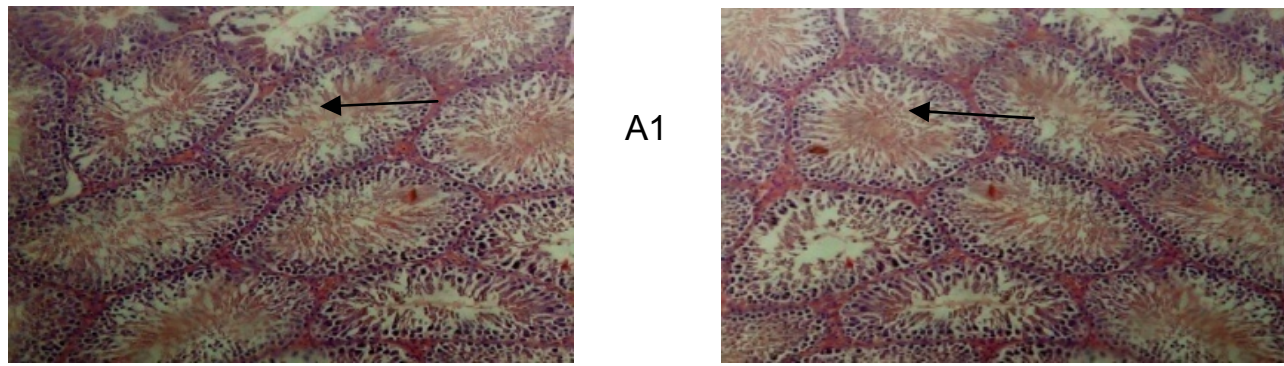

A2 
Agric. Biol. J. N. Am., 2010, 1(5): 859-865

Fig. 3: The histology of a cross section of the cortical region of the renal tissue of the control group BI and B2 animals treated with $500 \mathrm{mg} / \mathrm{kg}$ body weight of the extract. Arrow shows renal corpuscles with Bowman's spaces around it ( $\mathrm{H}$ and E stain) mag. $\times 100$.

B1

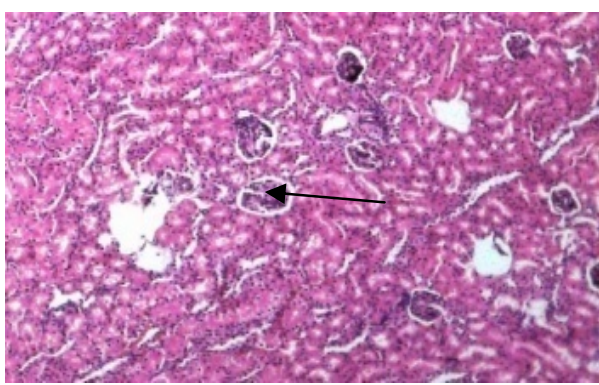

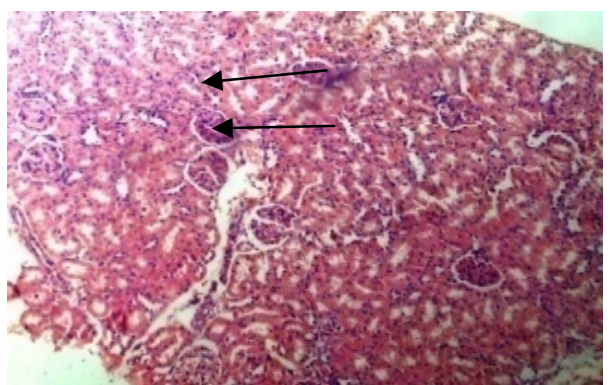

B2

Fig. 4: The cross section of the cardiac muscle of the control group $\mathrm{Cl}$ and $\mathrm{C} 2$ of the animals treated with $500 \mathrm{mg} / \mathrm{kg}$ body weight ( $\mathrm{H}$ and $\mathrm{E}$ stain). mag. $\mathrm{x} 100$.

C1
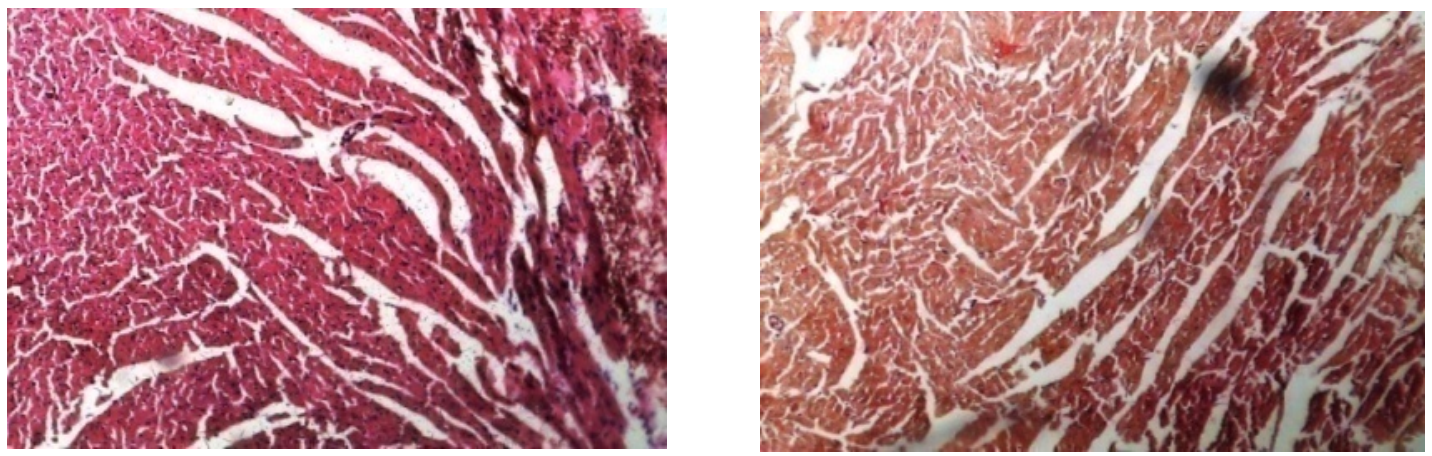

Fig. 5: The cross section of the hepatic tissue of the control group DI and D2 of the animals treated with $500 \mathrm{mg} / \mathrm{kg}$ body weight of the extract. Arrow shows the central vein, around it is hepatocytes radially arranged ( $\mathrm{H}$ and $\mathrm{E}$ stain). Magx100

D1

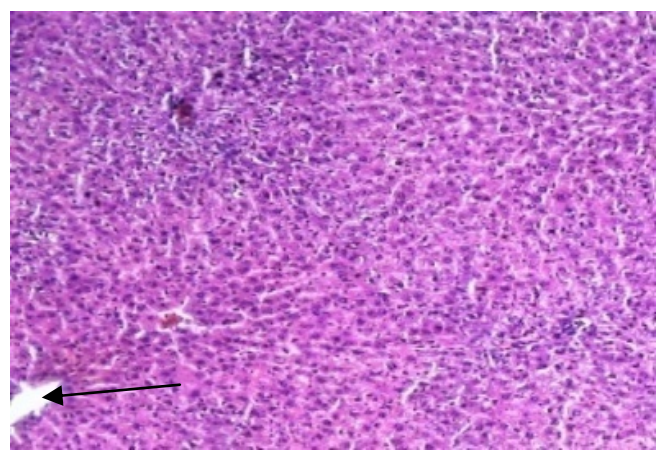

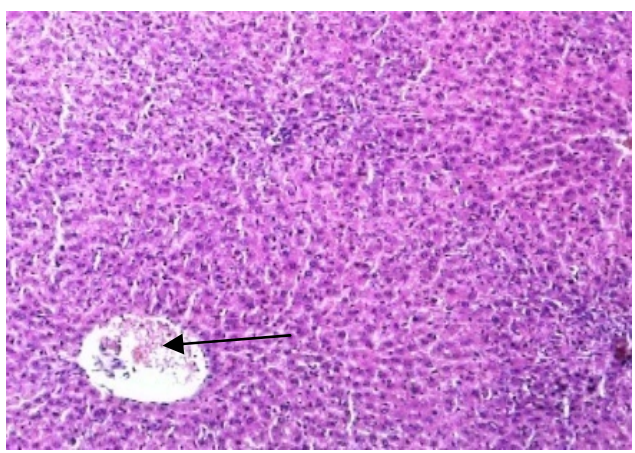

D2

Table 3: Effects of hydroethanolic extract of Chromoleana odorota on various organ weights after 35 days of subchronic toxicity study

\begin{tabular}{|c|l|l|l|l|}
\hline Dose $\mathbf{~ m g / k g ~ b w t ~}$ & Brain/100g bwt & Heart/100g bwt & Liver/100g bwt & Kidney/100g bwt \\
& & & & \\
\hline Control & $1.5 \pm 0.3$ & $0.6 \pm 0.1$ & $1.1 \pm 0.3$ & $1.1 \pm 0.1$ \\
100 & $1.2 \pm 0.1$ & $0.4 \pm 0.0$ & $4.1 \pm 0.5$ & $0.9 \pm 0.1$ \\
500 & $1.5 \pm 0.0$ & $0.6 \pm 0.0$ & $5.7 \pm 0.3$ & $1.1 \pm 0.1$ \\
& $1.1 \pm 0.1$ & $0.7 \pm 0.1$ & $4.1 \pm 0.4$ & $1.3 \pm 0.1$ \\
\hline
\end{tabular}


Agric. Biol. J. N. Am., 2010, 1(5): 859-865

\section{RESULTS AND DISCUSSION}

Modern medicine has offered tremendous advantages with wide range of application. Despite this, traditional medicine has maintained greater popularity all over developing world and the use is rapidly on the increase (Daswani et al.,2006). Beyond this, it is apparent that herbal medicines have received greater attention worldwide as alternative to clinical therapy in recent times leading to subsequent increase in their demand (Sushruta et al.,2006). In rural Nigerian communities, the exclusive use of herbal drugs prepared and dispensed by herbalists without formal training for the treatment of diseases is still very common (Ogbonnia et al., 2008). Experimental screening method is therefore important for ascertaining the safety and efficacy of these herbal products as well as to establish their active components.

The acute toxicity study of the extract indicated no changes in the behavior and in the sensory nervous system responses in the animals. Also no adverse gastrointestinal effects were observed in the male and female mice used in the experiment. All the mice that received $20.0 \mathrm{~g} / \mathrm{kg}$ dose of the extract died within $4 \mathrm{hr}$ while the animals that received $5.0 \mathrm{~g} / \mathrm{kg}$ dose survived beyond the 24 hours of observation. The median acute toxicity value $\left(\mathrm{LD}_{50}\right)$ of the extract was determined to be $16.501 \mathrm{~g} / \mathrm{kg}$ body weight. According to Ghosh (1984) and Klaasen et al. (1995) the extract could be classified as being slightly toxic, since the $\mathrm{LD}_{50}$ was found to lie between $5.0 \mathrm{~g}$ and $15.0 \mathrm{~g} / \mathrm{kg}$. The gram equivalence of the $\mathrm{LD}_{50}$ in an average adult man would translate to $1072.5 \mathrm{~g}$ dose of the drug. This is a very high value and makes the preparation relatively safe for use. The viscera of the dead animals did not show any macroscopic changes that could point to the cause of the death. However, since the animals did not convulse before dying, it postulated that the extract did not kill the mice by some action on the nervous system (Ogwal- Okeng et al., 2003)

The effects of the drug on the body weight variation of the treated animals was remarkable only on the groups that received higher doses of $C$. odorata, where there was initial increase followed by the decrease in weight. On the other hand, significant increase in weight was observed through out the experimental period in the groups that received lower doses compared to the control (Table 2 and Fig.1). The decrease in weight observed at day 20 in the group treated with highest dose could be attributed to the suppression of the animals' appetite by the extract. There was decrease in weight in the first 5 days in the group treated with a dose of $250 \mathrm{mg} / \mathrm{kg}$ bwt and when this effect was overcome there was a dramatic gain in weight which continued to the end of the studies.

Table 1: Acute toxicity study in mice with $C$. ordorata extract

\begin{tabular}{|l|l|l|l|l|}
\hline Group & $\begin{array}{l}\text { No. of } \\
\text { Mice }\end{array}$ & $\begin{array}{l}\text { Doses } \\
\text { of } \\
\text { extract }\end{array}$ & $\begin{array}{l}\text { Number } \\
\text { of dead } \\
\text { mice }\end{array}$ & $\begin{array}{l}\text { \% } \\
\text { Cumulative } \\
\text { dead of } \\
\text { mice }\end{array}$ \\
\hline 1 & 5 & Control & 0 & 0.0 \\
\hline 2 & 5 & 1.0 & 0 & 0.0 \\
\hline 3 & 5 & 2.0 & 0 & 0.0 \\
\hline 4 & 5 & 5.0 & 0 & 0.0 \\
\hline 5 & 5 & 10 & 0 & 0.0 \\
\hline 6 & 5 & 15 & 1 & 33.3 \\
\hline 7 & 5 & 20 & 2 & 10.0 \\
\hline
\end{tabular}

Table 2: Body weight variation of normal and treated rats with various doses of the extract during 35 days of subchronic toxicity study

\begin{tabular}{|c|l|l|l|l|l|l|l|l|}
\hline $\begin{array}{l}\text { Dose } \\
\text { kgbwt }\end{array}$ & Day 1 & Day 5 & Day 10 & Day 15 & Day 20 & Day 25 & Day 30 & Day 35 \\
\hline control & $150.1 \pm 2.7$ & $152.0 \pm 2.2$ & $154.6 \pm 1.8$ & $155.5 \pm 1.1$ & $157.6 \pm 2.5$ & $158.8 \pm 2.7$ & $158.8 \pm 2.2$ & $160.1 \pm 2.0$ \\
100 & $128.1 \pm 4.9$ & $133.0 \pm 6.6$ & $138.1 \pm 8.4$ & $139.0 \pm 3.1$ & $141.5 \pm 1.2$ & $142.1 \pm 1.6$ & $144.5 \pm 1.0$ & $145.1 \pm 2.5$ \\
250 & $154.1 \pm 7.4$ & $152.3 \pm 7.1$ & $163.2 \pm 5.4$ & $167.5 \pm 3.7$ & $168.1 \pm 4.6$ & $170.2 \pm 8.4$ & $174.3 \pm 8.0$ & $178.1 \pm 1.8$ \\
500 & $148.1 \pm 4.8$ & $150.1 \pm 7.6$ & $159.1 \pm 7.8$ & $165.3 \pm 6.2$ & $170.0 \pm 5.6$ & $167.0 \pm 5.3$ & $163.1 \pm 6.8$ & $160.7 \pm 8.3$ \\
\hline
\end{tabular}


Agric. Biol. J. N. Am., 2010, 1(5): 859-865

Table4: Effect of the administration of the extract on biochemical profile

\begin{tabular}{|l|l|l|l|l|}
\hline Parameter & Control & $\mathbf{1 0 0} \mathbf{~} \mathbf{g} / \mathbf{k g}$ & $\mathbf{2 5 0} \mathbf{~ m g} / \mathbf{k g}$ & $\mathbf{5 0 0} \mathbf{~ m g / k g}$ \\
\hline Glucose (Mmol/l) & $6.4 \pm 0.0$ & $5.5 \pm 0.0$ & $5.3 \pm 0.0$ & $4.8 \pm 0.0^{* *}$ \\
TotalCholest.(Mmol/l) & $1.0 \pm 0.0$ & $1.0 \pm 0.0$ & $1.0 \pm 0.0$ & $0.9 \pm 0.0$ \\
Triglycerides (Mmol/l) & $0.6 \pm 0.0$ & $0.7 \pm 0.0$ & $0.5 \pm 0.0$ & $0.9 \pm 0.0$ \\
HDL (Mmol/litre) & $0.9 \pm 0.0$ & $1.0 \pm 0$ & $1.0 \pm 0.0$ & $1.6 \pm 0.0^{*}$ \\
LDL (Mmol/litre) & $0.2 \pm 0.0$ & $0.2 \pm 0.0$ & $0.2 \pm 0.0$ & $0.2 \pm 0.0$ \\
Creatinine (Mmol/litre) & $74.9 \pm 1.5$ & $63.9 \pm 0.4^{*}$ & $58.3 \pm 2.5^{*}$ & $67.9 \pm 0.1^{*}$ \\
Total Protein (g/l) & $92.2 \pm 0.2$ & $80.0 \pm 0.5^{*}$ & $72.5 \pm 0.6^{*}$ & $72.5 \pm 0.6^{*}$ \\
ALT (U/L) & $86.7 \pm 0.2$ & $60.7 \pm 0.3^{*}$ & $61.1 \pm 1.1^{*}$ & $55.7^{*} 0.4^{*}$ \\
AST(U/L) & $186.2 \pm 1.2$ & $262.5 \pm 3.1^{*}$ & $394.1 \pm 1.0^{*}$ & $294.1 \pm 1.2^{*}$ \\
\hline
\end{tabular}

Mean $\pm \operatorname{sem}(n=5)$ : ${ }^{*} p<0.05$; ${ }^{* *} p<0.01 \mathrm{Vs}$ control group. Control group received $0.5 \mathrm{ml} 2 \%$ Tween 80 solution.

Table 5: Effect of the extract on haematological profile

\begin{tabular}{|l|l|l|l|c|}
\hline Dose & PCV \% & RBC 10 $\mathbf{I m m}^{3}$ & WBC 10 $\mathbf{m m m}^{3}$ & Haemoglobin $\mathbf{~ m g / d l}$ \\
\hline Control & $46.0 \pm 1.0$ & $6.1 \pm 0.4$ & $9.2 \pm 0.0$ & $15.2 \pm 0.3$ \\
$100 \mathrm{mg}$ & $40.0 \pm 0.4$ & $6.6 \pm 0.4$ & $6.8 \pm 0.0^{*}$ & $14.1 \pm 0.5$ \\
$250 \mathrm{mg}$ & $42.0 \pm 0.5 .0$ & $5.8 \pm 0.0$ & $4.4 \pm 1.0^{*}$ & $13.1 \pm 0.4$ \\
$500 \mathrm{mg}$ & $35.0 \pm 0.2 .1^{*}$ & $5.3 \pm 0.0$ & $5.0 \pm 0.0^{*}$ & $11.6 \pm 0.3^{*}$ \\
\hline
\end{tabular}

There were no morphological changes in the colour of the various organs of the treated animals compared to the control. However, changes in the various organs weights especially in kidney and liver occurred only in the animals that received the highest dose of the drug. The histological sections of the untreated testicular tissue (Fig. 2, Al) showed the seminiferous tubules cut in different planes having distinct boundary and separated by interstitium. The germinal epithelium showed compact arrangement of the differentiating primitive cells while the spermatozoa formed a cluster at the lumina. In Fig. 2, A2 (treated testes), there was no evidence of abnormal features both in the seminiferous tubules and the structures around it.

Fig. 3, B1 shows the photomicrograph of the untreated renal tissue, the cortical area appeared as a dense round mass separated from surrounding structures by Bowman's space. The extract treated (Fig. 3, B2) showed normal appearance with no morphological changes. The photomicrograph of the untreated cardiac muscle (Fig. 4, Cl) showed a longitudinal section of normal muscle fibres which branched to give appearance of three dimensional networks. The extract treated (Fig. 4, C2) showed similar appearance with no indication of cellular lesion or distortion. The photomicrograph of normal hepatic tissue (Fig. 5, DI) showed the portal tracts at the periphery of indistinct hepatic lobule. The hepatocytes radially arranged, continued from the lobular margins to the centre with each column interspaced by sinusoids. In the extract treated (Fig. 5 , D2), normal appearance of tissue histology was observed.
There was significant decrease $(p \leq 0.05)$ in the plasma protein level in all the treated animals which suggested that there was no sign of impaired renal function (Kachmar and Grant, 1982). Similarly, the decrease in the plasma creatinine concentration indirectly suggested no kidney damage specifically by renal filtration mechanism (Crook, 2006). Therefore, it was evident that the drug at doses employed did not cause renal impairment or kidney damage. ALT is released in the liver and an elevation in its plasma concentration suggests hepatic damage. The liver and heart release AST and ALT and an elevation in their plasma concentrations are indicators of hepatic and cardiac damage (Mythilpriya et al., 2007; Wasan et al., 2001). The significant decrease $(p \leq 0.05)$ in the ALT level evidently showed that no hepatic damage occurred which was also confirmed by the histological study. There was however, significant increase in the AST levels observed in all the treated groups compared to the control. The increase in the activity of the enzyme could have suggested a measure of toxic activity in the cardiac tissue (Tilkian et al., 1979; Crook, 2006) but this was not substantiated from the histological study.

The result of the lipid profile showed decrease in the plasma total cholesterol (TC) and triglyceride (TG) levels which might be attributed to the presence of hypolipidemic agents in the extract. The increase in HDL-cholesterol levels (anti-atherogenic agent) and a reduction in LDL-cholesterol levels observed in all the treated animals is an evidence that the drug can reduce the cardiovascular risk factors that contribute to the death of diabetic subjects (Barnett and O'Gara, 2003). The reduction of the cardiovascular 
risk factors gave further support as to the traditional use of the herbal formulation as an antidiabetic agent.

The observed significant $(p \leq 0.05)$ decrease in the haemoglobin levels in all the treated groups might be due to the decrease in iron absorption.

\section{CONCLUSION}

The high $\mathrm{LD}_{50}$ value obtained was a clear indication that the C.odorata could be safe for use. The study showed that the drug has some hypolipidemic activity and good reducing effects on cardiovascular risk factors. The study also revealed that the drug at doses investigated did not provoke toxic effects to the animals' liver and kidney.

\section{REFERENCES}

Barnett H. A and O'Gara G (2003). Diabetes and the Heart. Clinical Practice Series. Churchill Livingstone Edinburgh UK : 7-30.

Bürger C., Fischer D. R., Cordenunzzi D. A., Batschauer de Borba A. P., Filho VC and Soares dos Santos A. R. (2005). Acute and subacute toxicity of the hydroalcoholic extract from Wedelia paludosa (Acmela brasilinsis) (Asteraceae) in mice. J. Pharm Sci. (www.cspsCanada.org) 8, 2: 370-373.

Crook M. A (2006). Clinical Chemistry and Metabolic Medicine. $7^{\text {th }}$ Edition. Hodder Arnold, London: 426.

Daswani G. P., Brijesh S and Birdi J. T (2006). Preclinical testing of medicinal plants: advantages and approaches. Workshop proceedings on approaches towards evaluation of medicinal plants prior to clinical trial. Organized by the foundation for medical research at Yashwantrao Chavan Academy of Development Administration (YASHADA), Pune, India: 60-77.

Ekaidem I. S., Akpanabiatu M. I., Uboh F. E. and Eka O. U (2006). Vitamin B12 supplementation: effects on some biochemical and haematological indices of rats on phenytoin administration. Biokemistri 18, 1: 31- 37.

Farnsworth R. N (1966). Review on biological and phytochemical screening of plants. J. Pharm. Sci. 55: 225276.

Ghosh M. N (1984). Fundamentals of experimental pharmacology, $2^{\text {nd }}$ Edition. Scientific Book Agency, Calcutta; 154-157.

Harborne J. B (1998). Methods of extraction and isolation in: Phytochemical methods. London: Chapman and Hall, 6066.

Houghton P. J and Raman A (1998). Laboratory handbook for fractionation of natural extracts. Chapman and Hall, London, p. 199.

Hussain A and Eshrat H. M (2002). Hypoglycemic, hypolipidemic and antioxidant properties of combination of Curcumin from Curcuma longa, Linn and partially purified product from Abroma augusta, Linn. In streptozotocin induced diabetes. Indian J Clinical Biochem 17 (2): 3343.

Joshi C. S., Priya E. S and Venkataraman S (2007). Acute and subacute studies on the polyherbal antidiabetic formulation Diakyur in experimental animal model. $J$ Health Sc 53 (2): 245-249.

Klaasen C. D., Amdur M. O and Doull J (1995). Casarett and Doull's Toxicology: The basic science of poison. $8^{\text {th }}$ Edition. Mc Graw Hill, USA : 13 - 33.

Kachmar J. F and Grant G.H (1982). Proteins and Amino Acids. In: Tietz NW, (Ed.). Fundamentals of clinical chemistry. $2^{\text {nd }}$ ed, W.B. Saunders Company, Philadelphia, USA: 849-944.

Ling S. K, Mazura M. P and Saliah M (2007). Platelet activating factor (PAF) receptor-binding antagonist activity of the methanol extract from Chromolaena odorata (L.) King and Robin. Biological and Pharmaceutical Bulletin. 30:1150-1152.

Mythilypriya R, Shanthi P and Sachdanandam P. (2007). Oral acute and subacute toxicity studies with Kalpaamruthaa, a modified indigenous preparation on rats. J Health Sc. 53 (4): 351-358

Ogbonnia, S., Adekunle, A. A., Bosa M. K and Enwuru V. N (2008). Evaluation of acute and subacute toxicity of Alstonia congensis Engler (Apocynaceae) bark and Xylopia aethiopica (Dunal) A. Rich (Annonaceae) fruits mixtures used in the treatment of diabetes. African $\mathrm{J}$ Biotech. 7 (6): $701-705$.

Ogwal-Okeng W. J., Obua C and Anokbonggo W W. 2003. Acute toxicity effects of the methanolic extract of Fagara zanthoxyloides (Lam.) root-bark. African Health Sc. 3 (3): 124-126.

Pieme C. A., Penlap V. N., Nkegoum B., Taziebou C. L., Tekwu E. M., Etoa F. X and Ngongang J (2006). Evaluation of acute and subacute toxicities of aqueous ethanolic extract of leaves of (L) Roxb (Ceasalpiniaceae). African J Biotech. 5 (3): 283- 289.

Pisutthanan N., Liawruangrath S., Bremner B. J and Liawruangrath B (2005). Chemical constituents and Biological activities of Chromolaena odorata. Chiang Mai J Sci.32(2):139-148.

Silva L.G., Lee I. S and Kinghorn D. A (1998). Special problems with the extraction of plants. In: Methods in biotechnology natural product isolation. Cannell JPR (ed) Humana, Press Inc., Totowa, New Jersey, USA. 4: 329363.

Shah Ayub M. A., Garg S. K and Garg K. M (1997). Subacute toxicity studies on Pendimethalin in rats. Indian $\mathrm{J}$ Pharmacol. 29:322-324.

Sushruta K, Satyanarayana S, Srinivas N and Sekhar Raja J. (2006). Evaluation of the blood-glucose reducing effects of aqueous extracts of the selected Umbellifereous fruits used in culinary practice. Tropical Journal of Pharmaceutical Research 5,2: 613- 617

Tilkian M., Sarko C. B. M. and Tilkian G. A (1979). Clinical implication of laboratory tests. $2^{\text {nd }}$ Ed. The C.V Mosby Company, St Louis, Missouri, USA.

Wasan K. M., Najafi. S., Wong J and Kwong M (2001). Assessing plasma lipid levels, body weight, and hepatic and renal toxicity following chronic oral administration of a water soluble phytostanol compound FM-VP4, to gerbils. J Pharm Sci (www.ualberta.ca/ csps). 4 (3): 228-234. 